\title{
Surveying the Role of Positive and Negative Affection and Selective Processing of Information in Children with Conduct Disorder and Normal Kids
}

\author{
Kaveiy Mahdieh \\ M.A. in General Psychology, Department of Psychology, Faculty of Humanities, Neyshabur Branch, \\ Islamic Azad University, Neyshabur, Iran \\ Toozandehjani Hassan* \\ Assistant Professor, Ph. D. of Psychology, Department of Psychology, Faculty of Humanities, Neyshabur Branch, \\ Islamic Azad University, Neyshabur, Iran \\ *Corresponding Author Email: H. Toozandehjani@ymail.com
}

\author{
Doi:10.5901/mjss.2016.v7n3s3p111
}

\section{Abstract}

This study is one of the semi-empirical and causative-comparative researches in order to compare the positive and negative affection and orientation of attention or selective processing in kids with conduct disorder and normal kids. Of the kids who referred to psychiatric clinics and psychiatric service centers in the city of Nishabur, 50 kids with conduct disorder(Based on the diagnostic interview based on DSM-IV and interviews with KSADS) by reachable convenience samplingand they have been selected voluntarily. Normal samples were selected from students of Nishabur city's school by the multistage cluster. Positive and negative affection questionnaires, attention orientation, Stroop test and Recognition test in order of data collecting, was used. Data were analyzed using the $T$ test in independent groups. Results was shown that between kids with conduct disorder and normal kids by positive and negative affection and attention orientation or selective processing of information it was a meaningful difference. $(p<0.05)$

Keywords: positive and negative affection, attention orientation, conduct disorder

\section{Introduction}

According to Barlow's theoretical model (1988), anxiety and depression basically are emotional disorders and they are rooted in spontaneous and inappropriate shots of negative emotions (such as fear and sadness) in people who are biologically have over reactions in stressful life events. Although the nature of turmoil emotions in various disorders has different arise, must forms of mental pathology, Reflect dysfunction in some areas such as emotional processing and emotional response. (Crinck and Bachurosckey,1999) The primary concern of people with panic disorder, is related to their threatening nature of physical sensitivities in themselves. (Clarck, 1986; quoted from Bahrami and Nick yar, 2005)

According to cognitive model, in conduct disorder there is an expectation to occurrence of a negative or harmful event, which is called by perception of threat. (Beck, Emery, Greenberg, 1985)People perceive of a threat based on their mental judgment of "possibility" of negative occurrence and "Intensity" or "hatred" from that event. However it is possible that such hyperbolized judgments are associated with highest level of emotional disorders, several theorists believe that mental judgments in conduct disorder are particular (quoted from Harris, 2001).

Conduct disorder during childhood and adolescence is associated with significant difficulties in the functioning of people. (Schneider et al., 1992).Also, conduct disorder in adolescents is associated with depression disorder (Isao, Conrad and Peterman, 1999). These findings show that conduct disorder during childhood and adolescence is associated with significant difficulties in the functioning of people. Results of several researches has shown emotional states is effected on a number of cognitive variables such as free association, attention and interpretation of ambiguous events, although conduct disorder usually begins during childhood and adolescence (Schneier et al., 1992; quoted from Ostovar, 2006).

Self-focused attention, refers to increase personal awareness of internal cognitive events, awareness of mobility in the past and present, awareness of more or less information of mind such as personal perspectives and mind provisional data. And the focused attention on out to raise awareness of one's thoughts, feelings and personal behavior self besides through the processing of other information, is called (Mobini, 1993). 
In addition, the intensity of conduct disorder in children and adolescents is associated with several problems at school (Lost and Strauss, 1990).Conduct disorder in adolescents is associated with depression (Isao, Conrad and Peterman, 1999).Conduct disorder during childhood and adolescence is associated with significant difficulties in people's functioning (quoted from Ostovar, 2006)

Positive affection with extraversion personality trait and negative affection with Trait neuroticism is not correlate. These correlations between the emotions and traits of personality are observing and from 4.0 to 9.0 are fluctuate. Negative affect in late adolescence reaches its peak and then after age it decreases at least until the middle of adulthood. There are individual differences in positive and negative affection and in short time term oscillations has been seen in positive creation that follows circadian cycle (day low) and this point is related to a process which by that particular incentives in internal and external environment has been chosen for further processing. Selective attention is related to early sifting through the incentive more than its continuation. Both the positive and negative affection show the experimental components of biological-neural system that evolved to address the developmental tasks (Watson et al., 1988). Negative affection (such as neuroticism personality traits) one aspect of behavioral inhibition system and facilitate avoid orientation. Function of this system is to start an avoidance system and behavioral inhibition bothering to isolate living creatures from dangerous situations, pain or punishment. In contrast, positive affection is a part of behavior facilitating system (such as extraversion) that leads living creatures into potentially rewarding opportunities that leads them into pleasure. Many negative emotions such as anxiety and anger won't limit the deposits of thinking-take action of people so that they prepare to act their specific method of self-protection, in contrast, positive emotions will expand the deposits of thinking-take action. This expansion of thinking-take action deposits provide to build opportunities for sustainable personal resources which in turn is a basis for personal growth and transformation with emotion's positive or compromise twists and turns to identify and to take an action (Bahrami, Nick yar, 2005).

Considering the fact that there are a few researches in our country in the positive and negative affectivity and selective processing of information or selective attention of children with conduct disorder, has been done, hence to better understanding of cognitive biases, information's selective processing and conduct disorder's continuity in these children, doing this study seems necessary.

\section{Materials and Methods}

This research is one of the semi-empirical and causative-comparative to survey the role of orientation attention or selective attention and positive and negative affectivity in kids with conduct disorder and normal kids in 2013 in Nishabur city. Statistical Society of this study is all of the kids with conduct disorder which during the last quarter of 2013 (January, February and March) have been referred to private clinics, psychiatric and psychological services. Also, the population of normal people contains all of the elementary schools students of Nishabur city. The sample of this study contains 50 children with conduct disorder (children 8 to 12 years) which has been selected from statistical Society's kids (based on diagnostic interviews, interviews with KSADS) by reachable sampling and voluntary and also 50 normal children which has been selected by multistage cluster sampling form students of elementary schools of Nishabur city.

In this study, data collecting was based on emotional Stroop and Focus Attention Questionnaires (FAQ) were used.

Semi-structured clinical interview SCID: this interview has been set based on America's Psychiatric Association's Diagnostic and Statistical Manual of psychopathy fourth edition (DSM-IV) which in addition to facilitating the assessment process and identify sources, it provides the reliability and validity of a clinical interview. In this interview questions are closed (Khaki 2000, quoted from Sharifi, Asa'adi, Mohamadi et.al, 2003). In addition on of the goals of this designing Tools creators was interviews which were structured yes easy for clinicians (Spitzer \& Williams, 1992; quoted from Frisch, 1994). SCID has been provided by nearly 400 studies and researches. In Pasha Sharifi's studies and his et al (1998) which this interview has been done with the aim of Reliability Assessment and Functionality, in the first stage, tools translation and reliability surveying between cultures and in second stage of study, reliability and functionality of Persian translation in Iran's clinical population was investigated. Results showed the acceptable reliability of diagnosis with Persian version and its acceptable functionality which represents the ability to use these tools in the diagnosis of clinical investments, research and educational (quoted from Aboulghasemi, 2003).

Strength and difficulties questionnaire (SDQ): this questionnaire was built based on diagnostic criteria (ICD-10) in Britain in 1997 and was used for ages 3 to 16 years (Goodman, 1997). It has five subscales that are: emotional symptoms, conduct problems, hyperactivity, attention deficit, problems with peers and community-friendly practices (strengths child).The advantages of this questionnaire can be mentioned as short but comprehensive, diagnostic power and well reliability despite its shortness, four forms of peer self-report of teacher and parents, translating into forty 
languages, easy to use, scoring the strengths of children, in addition to behavioral problems, matchingits small scale of materials with International classification disease (ICD-10) and using the same material in nearly all of the materials in all four forms(quoted from Nassiry \& et al, 2006).

In Fleetlitch-Bilk's study (2004) the twice run solidarity of parents SDQ questionnaire with the average of 19 days' time interval was equivalent to70.9. The overall reliability of the teacher's form in the Becker study and his colleagues (2000) was 82.0 and reliability of its subscales was reported between 75.0 to 87.0 . Shahmorady (2006) with the implementation the two forms of teachers and parents, reported the reliability based on Cronbach's alpha for parents' form42.0 and 36.0 for teachers. In Mohammadi's research (2006) overall reliability for self-report form based on Cronbach's alpha 60.7 and for its subscales which means the emotional symptoms, conduct problems, hyperactivity, attention deficit, problems with peers and strengths(prosocial behavior),respectively are 56.0, 38.0, 49.0, 34.0, 50.0, (quoted from Nejat \& et al, 2006).

Positive and Negative Affect Scale (PANAS): this scale has been developed by Watson, Clark and Tligen (1988) and there were 20 emotions (10 positive emotion 10 negative emotion) examined. Rating this scale is done over a fivepoint scale (very low, low, medium, high and very high). Cronbach's alpha of this scale in Sohrabi and Hosseini's research (2002) was reported equivalent to 85.0. Aboulghasemi (2003) report the components internal correlation coefficient and all the scales between 74.0 to 94.0 . The validity of this tools has been presented with the correlation between the positive affect and negative affect with some of research tools that measure the structure associated with these two scales (like stress). For example negative affectivity associated with the Hopkins Symptoms Checklist (HSCL) 72.0 and correlation of positive affect with Taylor manifest anxiety scale -0.35 has been reported (quoted from Abolghasemi (2003)). Scale of Cronbach's alpha in this present study for positive affect 0.83 and for negative affect 0.82 has been obtained to measuring the positive effect of PA and negative effect of NA in children and adolescents in 8 to 15 years, age differences. Positive affect: you should sum the rating of 1,3,5,9,10,12,14,16,17 articles together. Negative affect: you should sum the ratings of 2, 4, 6,7,8,11,13,15,18,20 articles with each other.

To describe the triable demographic characteristics, the descriptive statistics (such as average, standard deviation and histogram) was used. To analysis data from inferred statistics (such as Kolmogorov, Smirnov, the T test in independent groups, Levene test, Men Witney).

Table1. Kolmogorov. Smirnov for conduct disorder

\begin{tabular}{cccccc}
\hline \hline $\begin{array}{c}\text { Positive } \\
\text { affectivity }\end{array}$ & $\begin{array}{c}\text { Negative } \\
\text { affectivity }\end{array}$ & $\begin{array}{c}\text { Attention } \\
\text { orientation }\end{array}$ & $\begin{array}{c}\text { Outside focused } \\
\text { attention }\end{array}$ & $\begin{array}{c}\text { Emphasize focused } \\
\text { attention }\end{array}$ & Z Statistics of Kolmogorov. \\
Smirnov test
\end{tabular}

Results of table1 shows a significant level of the research's variables are more than05/0. Thus, null hypothesis of the Kolmogorov-Smirnov test will be accepted based onthe normality of the observations to those mentioned cases in conduct disorder $(P>0.50)$. Statistic Kolmogorov-Smirnov test in the table above for outside focused attention is less than amount of the normal table. So assuming the normality in this case is not approved. Therefore, for comparing the conduct disorder with normal kids we can use the Classic test. In fact in this case to compare groups we should use the nonparametric tests

Table 2. Kolmogorov-Smirnov test for normal kids

\begin{tabular}{cccccc}
\hline \hline $\begin{array}{c}\text { Positive } \\
\text { affectivity }\end{array}$ & $\begin{array}{c}\text { Negative } \\
\text { affectivity }\end{array}$ & $\begin{array}{c}\text { Attention } \\
\text { orientation }\end{array}$ & $\begin{array}{c}\text { Outside focused } \\
\text { attention }\end{array}$ & $\begin{array}{c}\text { Emphasize focused } \\
\text { attention }\end{array}$ \\
\hline $0 / 679$ & $0 / 839$ & $0 / 712$ & $1 / 776$ & $0 / 612$ & $\begin{array}{c}\text { Z Statistics of Kolmogorov. } \\
\text { Smirnov test }\end{array}$ \\
\hline $0 / 746$ & $0 / 482$ & $0 / 692$ & $0 / 004$ & $0 / 848$ & $\mathrm{p}$-value \\
\hline \hline
\end{tabular}

Due to this significance level for all variables except for outside focused attention is more than 0.50 , so the normal assumption for emphasize focused attention, attentional bias, negative and positive affectivity will be accepted. About the outside focused attention variable, normality hypothesis is rejected. So to compare the observation of normal kids and 
kids with conduct disorder, the non-parametric tests such as Wilcoxon, was used.

Table 3. $T$ test for comparing two independent sample in negative affect scale

\begin{tabular}{|c|c|c|c|c|c|c|c|}
\hline \multicolumn{3}{|c|}{ T-test for means equality } & \multicolumn{4}{|c|}{$\begin{array}{l}\text { Levene test for equality of } \\
\text { variance }\end{array}$} & \multirow{3}{*}{ Negative affectivity } \\
\hline \multicolumn{2}{|c|}{$\begin{array}{l}\% 95 \text { confidence interval for the } \\
\text { difference }\end{array}$} & \multirow[t]{2}{*}{ - p-amount } & \multirow{2}{*}{$\begin{array}{l}\text { Freedom } \\
\text { degrees }\end{array}$} & \multirow{2}{*}{$\begin{array}{c}\text { statistic } \\
\mathrm{t}\end{array}$} & \multirow[t]{2}{*}{$p$-amount } & \multirow[t]{2}{*}{ F statistic } & \\
\hline High & Low & & & & & & \\
\hline$-3 / 53$ & $-8 / 54$ & $0 / 00$ & 98 & $-4 / 79$ & $0 / 30$ & $1 / 10$ & $\begin{array}{l}\text { Reception equal } \\
\text { variances }\end{array}$ \\
\hline$-3 / 53$ & $-8 / 54$ & $0 / 00$ & 98 & $-4 / 79$ & $0 / 30$ & $1 / 10$ & $\begin{array}{l}\text { Reception equal } \\
\text { variances }\end{array}$ \\
\hline$-3 / 52$ & $-8 / 54$ & $0 / 00$ & $94 / 54$ & $-4 / 79$ & & & Denied equal variances \\
\hline
\end{tabular}

Results of table 3 suggest the assumption of variances quality will accept due to Levine test statistics. In other words the Fisher statistics amount $(\mathrm{f}=1.097)$ is less than its corresponding amount in Fisher table $(\mathrm{F}=3.93)$. So the null hypothesis is accepted for equal variances of the two samples with each other. Since the absolute value of the calculated statistics (t=79.4) in this table it is more than the corresponding in the Student's $t$ table ( $t=1.98)$. Thus, it concluded with the possibility of $95 \%$ that between the studied variables is a significant difference. According to the collected data, considering the significance of the null hypothesis, researchers hypothesized that "negative affect on children with conduct disorder is higher than normal children" will be accepted.

Table 4. $T$ test for comparing the two independent sample in positive affectivity scale

\begin{tabular}{|c|c|c|c|c|c|c|c|}
\hline \multicolumn{3}{|c|}{ T-test for means equality } & \multicolumn{4}{|c|}{$\begin{array}{l}\text { Levine test for equality of } \\
\text { variance }\end{array}$} & \multirow{3}{*}{ Positive affectivity } \\
\hline \multicolumn{2}{|c|}{$\begin{array}{l}\% 95 \text { confidence interval for the } \\
\text { difference }\end{array}$} & \multirow{2}{*}{$p$-amount } & \multirow{2}{*}{$\begin{array}{l}\text { Freedom } \\
\text { degrees }\end{array}$} & \multirow{2}{*}{$\stackrel{\text { statistic }}{t}=$} & \multirow{2}{*}{$\mathrm{p}$-amount } & \multirow{2}{*}{ statistic F } & \\
\hline high & low & & & & & & \\
\hline $4 / 769$ & $-1 / 31$ & $0 / 262$ & 98 & $1 / 116$ & \multirow[t]{2}{*}{$0 / 336$} & \multirow[t]{2}{*}{ 0/773 } & $\begin{array}{l}\text { Reception equal } \\
\text { variances }\end{array}$ \\
\hline $4 / 770$ & $-1 / 31$ & $0 / 262$ & $95 / 205$ & $1 / 116$ & & & Denied equal variances \\
\hline
\end{tabular}

Results of the table 4 shows that the assumption of equality of variances is accepted based on the Levine test. In other words the statistic of amount of Fisher ( $F=0.733)$ is less than its corresponding value in Fisher's table ( $F=3.39)$. So the null hypothesis will be accepted based on variances equality of those two samples with each other. Since the absolute amount of the calculated statistic ( $\mathrm{t}=1.116)$ is more than its corresponding amount in T Student Table ( $\mathrm{t}=1098)$. Thus, it will be conclusion with the $95 \%$ possibility that there is a significant difference between variables. According to the collected data and with considering to the significance of the null hypothesis, researchers hypothesized based on "positive affect on children with conduct disorder than children with normal lower" will be rejected.

Table 5. summarizes the results of t-test scores for attention (focused attention on the inside)

\begin{tabular}{|c|c|c|c|c|c|c|c|}
\hline \multicolumn{5}{|c|}{ T-test for means equality } & \multicolumn{2}{|c|}{$\begin{array}{c}\text { Levine test for equality of } \\
\text { variance }\end{array}$} & \multirow{3}{*}{$\begin{array}{l}\text { First hypothesis } \\
\text { Focused attention on the } \\
\text { inside }\end{array}$} \\
\hline$\% 95$ confid & al for the & \multirow{2}{*}{$\begin{array}{c}\mathrm{p}- \\
\text { amount }\end{array}$} & \multirow{2}{*}{$\begin{array}{l}\text { Freedom } \\
\text { degree }\end{array}$} & \multirow[t]{2}{*}{ statistict } & \multirow[t]{2}{*}{ p-amount } & \multirow[t]{2}{*}{ Statistic F } & \\
\hline High & Low & & & & & & \\
\hline$-0 / 605$ & $-3 / 73$ & $0 / 008$ & 98 & $-2 / 73$ & \multirow{2}{*}{ 0/012 } & \multirow{2}{*}{$6 / 72$} & Reception equal variances \\
\hline$-0 / 602$ & $-3 / 73$ & $0 / 008$ & $86 / 25$ & $-2 / 73$ & & & Denied equal variances \\
\hline
\end{tabular}


The above table's results shows that the assumption of equality and variances will be rejected by the statistics of Levene test. In other words the amount of Fisher's statistic $(\mathrm{F}=6.72)$ is more than its corresponding value in Fisher table ( $\mathrm{F}=3.39)$. So the null hypothesis of equal variances of the two samples will be reject. Since the absolute value of calculated $T$ statistic $(t=2.73)$ in this table is more than its corresponding value in $T$ Student $(T=1.98)$. Thus, it will be conclusion with the $95 \%$ possibility that there is a significant difference between variables. According to the collected data and with considering to the significance of the null hypothesis, researchers hypothesized based on "Focused attention on the inside in conduct disorder is higher than the normal group" will be accepted.

Table 6. Summarizes the results of the Mann-Whitney to compare two groups by nonparametric method

\begin{tabular}{|c|c|c|c|c|}
\hline The statistically level & The test statistic & Statistic & Posts Reputation & \\
\hline & $816 / 5$ & the Mann-Whitney statistic & $59 / 17$ & Normal kids \\
\hline \multirow[t]{2}{*}{ 0/003 } & $2091 / 5$ & Wilcox on statistic & $41 / 83$ & Conduct disorder \\
\hline & $-3 / 004$ & Statistic Z & & \\
\hline
\end{tabular}

The results of above table shows that the calculated statistic for comparing the normal kids and kids with conduct disorder by nonparametric method $(Z=-3.004)$ is more than its corresponding statistic in Standard table $(Z=1.96)$. Thus, it will be conclusion with the $95 \%$ possibility that there is a significant difference between variables. According to the collected data and with considering to the significance of the null hypothesis, researchers hypothesized based on "The outside focused attention in kids with conduct disorder is less than the normal kids" will be accepted.

Table 7. The T test for comparing to independent samples in selective attention or attention bias

\begin{tabular}{|c|c|c|c|c|c|c|c|}
\hline \multicolumn{3}{|c|}{ T-test for equality of means } & \multirow{3}{*}{$\begin{array}{c}\text { Freedom } \\
\text { degree }\end{array}$} & \multirow{3}{*}{ stitistict } & \multicolumn{2}{|c|}{$\begin{array}{l}\text { Levene test for equality of } \\
\text { variance }\end{array}$} & \multirow{3}{*}{$\begin{array}{l}\text { Third hypothesis: } \\
\text { Attentional bias }\end{array}$} \\
\hline \multicolumn{2}{|c|}{$\begin{array}{l}\text { \%95confidence interval for the } \\
\text { difference }\end{array}$} & \multirow[t]{2}{*}{$p$-amount } & & & \multirow[t]{2}{*}{$p$-amount } & \multirow[t]{2}{*}{ Statistic F } & \\
\hline High & Low & & & & & & \\
\hline$-2 / 33$ & $-7 / 17$ & $0 / 00$ & 98 & $-3 / 91$ & \multirow[t]{2}{*}{$0 / 052$} & \multirow[t]{2}{*}{$3 / 75$} & $\begin{array}{l}\text { Reception equal } \\
\text { variances }\end{array}$ \\
\hline$-2 / 34$ & $-7 / 17$ & $0 / 00$ & $92 / 64$ & $-3 / 91$ & & & Denied equal variances \\
\hline
\end{tabular}

The results of above table shows that the assumption of equality and variances will be accepted by the statistics of Levene test. In other words the amount of Fisher's statistic $(\mathrm{F}=3.75)$ is less than its corresponding value in Fisher table $(\mathrm{F}=3.39)$. So the null hypothesis of equal variances of the two samples will be accepted. Since the absolute value of calculated $T$ statistic ( $t=-3.39)$ in this table is more than its corresponding value in $T$ Student $(T=1.98)$. Thus, it will be conclusion with the $95 \%$ possibility that there is a significant difference between variables. According to the collected data and with considering to the significance of the null hypothesis, researchers hypothesized based on "Attentional bias in children with conduct disorder is higher than normal children" will be accepted.

Table 8. Comparing two groups in scale of focused attention of inside and outside

\begin{tabular}{ccccccc}
\hline \hline Coefficients.exp & $\begin{array}{c}\text { Significance } \\
\text { level }\end{array}$ & $\begin{array}{c}\text { Freedom } \\
\text { degree }\end{array}$ & $\begin{array}{c}\text { Estimated } \\
\text { parent }\end{array}$ & $\begin{array}{c}\text { Standard } \\
\text { deviation }\end{array}$ & $\begin{array}{c}\text { Estimating } \\
\text { coefficients }\end{array}$ \\
\hline $0 / 232$ & $0 / 509$ & 1 & $0 / 430$ & $2 / 207$ & $1 / 43$ & Constant coefficient \\
\hline $1 / 165$ & $0 / 017$ & 1 & $5 / 473$ & $0 / 064$ & $0 / 149$ & $\begin{array}{c}\text { Focused attention on the } \\
\text { inside }\end{array}$ \\
\hline $0 / 795$ & $0 / 005$ & 1 & $7 / 267$ & $0 / 082$ & $-0 / 225$ & $\begin{array}{c}\text { Focused attention on the } \\
\text { outside }\end{array}$ \\
\hline $1 / 087$ & $0 / 045$ & 1 & $3 / 344$ & $0 / 045$ & $0 / 084$ & Attentional bias \\
\hline $1 / 07$ & $0 / 039$ & 1 & $4 / 189$ & $0 / 040$ & $0 / 084$ & Negative affectivity \\
\hline $0 / 980$ & $0 / 611$ & 1 & $0 / 254$ & $0 / 034$ & $-0 / 016$ & Positive affectivity \\
\hline \hline
\end{tabular}




\section{Discussion and Conclusion}

About the negative affectivity in kids with conduct disorder, the results of this research was consist with Barlow's finding (1988) which believe that anxiety and depression in this kids are basically emotional disorders ant they are root to spontaneous and disproportionate shots (like sadness and fear) that naturally show more respond to stressful life events. (Quoted from Kring \& Bachorowski, 1999; quoted from Bahrami \& Nikyar, 2005).

Sohrabi and Hosseini (2002) found in a research that in kids with conduct disorder there is a significant negative relation. Among negative affect and family relationships and between positive affect and family relations there is a significant positive relation. Watson, Clark and Tolgen (1988) in research found that the positive affect is indicative of a person's enjoyable interactions with environment that consequently make the person feel active and enthusiastic and feel more satisfy in life. In contrast people with high level of negative affection in interaction with environment feel stressed and experience more dissatisfaction. There is a significant relation between positive affect and the quality of kids with conduct disorder. It means that the more positive affect that they have instead of negative affect, their life quality will behavior able. Also, there is a significant relation between positive affect and life quality's subscale (physical health, mental health, relationships with others and relations with the environment). Research's findings is coordinate with studies of, Bernnan et.al (2006); Ito, Casiopo and Long (1998); Cassidy and Shower (2002); Watson and Clark and Toligen (1988); Stonge (1981); Fourguss (1999); Caman and Flite (1983); Dinner et.al (2000); Liver, Glaser, Roberts (2008); Argyle (2001); Hosseini \& hosseini (2002) Sohrabi \& Hosseini (2002); Farahani, Mohammad khani, Joekar (2009) and Mozaffari and Hadian fard (2004).

These finding can be explained based on two affectivity factors (Pleasant-Unpleasant and motivation in negative or positive affectivity) Watson, Clark and Toligen (1988). In this regard, although positive and negative affect seems like two contrasting mood factors and are strongly correlated, but these two factors are and distinct dimensions. Positive emotions that spread the deposits of thinking-action, pleasure, passion and joy of life that leads to build new sources in a person (Mirzahosseini et al, 2007).

Negative affect have adversely effects on the life quality of kids with conduct disorder and cause them a dissatisfaction in their lives. Negative affect have implication on sadness and lethargy and shows one aspect of internal discomfort and a displeased occupation. Negative affect is related to stress, health complaints, prevalence of adverse events in kids with conduct disorder. Negative affect contains a extensively range of negative behavioral modes such as fear, humiliation and hatred. Kids with these characteristics have low self-esteem in social interactions and they always feel lonely and they are unsatisfied about their lack of communication ability. These people in interact with environment have not any physical security and they are unsatisfied with their life. Negative experiences of the character is related to increase the ill feeling and other negative feelings, lack of self-sufficiency and avoidance behaviors (Farahani, Mohammadkhani, \& Jokar, 2009).

Johnson and Osit (1982) done a research on 34 kids with conduct disorder. Results showed that kids with conduct disorder are more sensitive to their physiologic changes, have less self-sufficiency and they assume themselves weak. For example kids with conduct disorder may consider their performance as a weak performance, because they clearly seem weak and or their standards is very strict and inaccessible (Haymberck, Dodge, Becker, 1986). So many studies shown that extraversion with positive affectivity and neuroticism with negative affectivity has a significant relation. (Kasta \& McCrea 1980; Larsen \& Metlar 1991; Rasting and Larsen 1995, 1997; Rasting 1999; Gomez \& et. Al 2000; Rabinson et.al 2007; quoted from Rafiee nia, 1387).

In kids with conduct disorder positive affectivity in related to personality trait extraversion and negative affectivity is related to trait neuroticism. These relations between positive affect and major characteristics character are noticeable and they are oscillate from 0.4 to 0.5 . Telligen (1995) believes that these two factors which means the emotionality positive or negative in kids with conduct disorder, matches the emotions attributes aspects. Positive affect and negative affect are traits that is consistent with personality factors (extraversion and neuroticism). It is a belief that the mental health field has three properties: it is within the individual experience of a person, evaluation of positive cases. It contains an overall assessment of all aspects of a person's life (McCullough, Huebner \& Laughing, 2000).

Preliminary studies indicate that the two structure, both the positive and negative effects are independent in children with conduct disorder. Positive affect in kids is refers to euphoria, alertness and activity and it has subsidiary friendliness dimensions (such as cheerful, lively and happy) self-reliance (such as reliable, strong and bold) vigilance (alert, focused and determined) (Grant, 2008). Brennan, Singh Spencer \& Thomson believes despite that the positive and negative affect have separate dimensions, but both of them are effective in life quality of kids with conduct disorder (McCullough, Huebner \& Laughing, 2000).

Ito, Cacioppo and Long (1998) in a research showed that both of the positive and negative affect are related to 
conduct disorder kids' motivation. Positive affect has a positive relation and negative affect has a reverse and significant relation. Campbell, Converse and Rodgers (1976) in a study found the kids with conduct disorder that have sufficient physical health, their positive affect increases and they experience a satisfying life.

Fredrickson and Losada (2005) believe that the positive affect leads to increasing creativity, Cognitive flexibility, efficiency in decision making and problem solving in kids with conduct disorder. Seligman and Csikszentmihalyi (2000) have been highlighted the importance of studying, the role of positive affect in life quality of kids with conduct disorder with beginning the positive psychology movement. Kenny and Ronald (2008) found that higher levels of commitment and life satisfaction with higher levels of consistent positive affect and lower levels of consistent negative affect, are related, in kids with conduct disorder. (quoted from Soltanizadeh, Malekpour, \& Neshat doost, 2008).

Forges (1999) in a research found out that kids with conduct disorder that have higher levels of positive affect are more participate in joyful activities, satisfying and quiet, they like each other more and their communication quality is better and not in line with positive affect's desire, also it helps decreasing the negative affect and its destructive effects.

In a study Kaman \& Fleet (1983) found that kids with conduct disorder that have high levels of positive affect, feel closer with others and they feel confident and loved. These kids not only have more social interaction with others, but their communication quality, is higher than the kids with lower levels of positive affectivity. Kids with conduct disorder that have high positive affectivity, feel closer to others and the like to communicate with people, they don't feel lonely, and over all see a satisfying life or they experience a joyful mood. Positive affectivity shows that how much passion in life a person has and how much of activity and consciousness a person has. Positive affect is an expression of active energy, daily activities and employment. Positive affect is thoughts reflecting, and positive feelings about life. (Rapple, 2003).

Positive affect has dimensions such as joy, happiness, vitality, self-confidence (such as courage, strength and confidence) and awareness (such as a focus and determination). (Diener, Sue, Hockas and Smith, 1998; Quoted from Mozaffari \& Hadian fard, 2004).

According to the results of the research, potential reason for outside focused attention in kids with conduct disorder than normal kids is that they are concern about the social impact which leads them into the inner thoughts and attitudes. And about the second hypothesis, the outside focused attention in kids with conduct disorder is mostly because of the mental involvement which they have in order of social interactions, and they look at themselves from another person's point of view and they humiliate themselves and they relate any problem in the relation to themselves (like taking a test and the attention to internal aspects and not to blame the external environment). This shows a significant relation. (Quoted from Mozafari \& Hadian fard, 2004).

\section{References}

Abolghasemi, F. (2003). Standardization of Positive and Negative Affection and its Simultaneous Validation with Mental Health Scale and Liveliness in Students of Isfahan University. M. A. thesis, general psychology course, Isfahan University.

Argyle, M. (2003). Psychology of Happiness. Translated by M Gohari Anaraki et al. Isfahan: Jahad Daneshgahi Publications. (Date of main work publication, 2001).

Bahrami, F. \&Nikyar, H. (1384).Metacognitive behavioral therapy for bipolar disorders. Isfahan: Mani Publications.

Barlow, D.H. (1988). Anxiety and its disorder the nature and treatment of anxiety and panic. New York: The Guildford press.

Brennan, D.A., Singh, K., Spencer, A. J., \& Thomson, K. F. R.(2006). Positive \& negative Affect and oral health-related quality of life.

Campbell, A. (1976). Subjective measures of well-being in American: recent Patterns and trends. New York: Mc Grow- Hill.

Diener, E. (2000). Subjective Well-Being: the science of Happiness and a personal for a national Index. American Psychologist, 55-3443.

Diener, E. Suh, E., Lucas, R. E., \& Smith, H. L. (1999). Subjective Well- Being: Three decades of progress 1967-1997. Psychological Bulletin. 125, 276. 302.

Diener, E., Suh, E., Lucas, R. E., \& Smith, H. L. (2000). Subjective Well- Being: Three decades of progress 1967-1997. Psychological Bulletin. 125, 276. 302.

Farahani, M; Mohammadkhani, Sh, and Jokar, F. (2009). The Relationship between Life Satisfaction and Quality of Life and Mental Wellbeing of Tehran teachers. Scientific and Research. Journal on Psychological Health, Vol 3, NO. 1, Spring, pp. 6-14.

Forgas, J.P. (1998). On being happy and mistaken: Mood effects on the fund mental attribution error. Journal of personality and social Psychology. 75, 318-331.

Forgas, J.P. (1999). On feeling good and being rude: affective influences on language use and request formulation. Journal of personality, 76, 928-939.

Forgas, J.P. (1999). On feeling good and being rude: affective influences on language use and request formulation. Journal of personality. 76, 928-939.

Frisch, M.B (1994). Quality of life inventory (QOLIm). National computer systems, Minneapolis, MN.

Harris, P. (2001). Emotional Development of Children. Translated by Mohammad Yamani and Mohammad Davoodi. Tehran: Training Teacher University Publications. 
Harris, P. (2001). Emotional Development of Children. Translated by Mohammad Yamani and Mohammad Davoodi. Tehran: Training Teacher University Publications.

Ito, T.A., Cacioppo, J. t. \& Lang, P.J. (1998). Electing affect using the International Affective Picture system: Trajectories through evaluative space. Personality and social psychology Bulletin, 24, 855-849.

Kamman, R.,\& flett, R. (1983). Affectometer 2: a scale to measure current level of general happiness. Australian Journal of Psychology. 35,259-265.

McCullough, G.,Huebner. E.S., \& Laughing, J.E. (2000). Life events, self-concept and adolescents subjective well-being. Psychology in the schools, 37, 281-297.

Mirza Hosseini, H; Delavar, A; Ahadi, H, and Maher, F. (2007). Determinants of Mental Well-being: The Role of Physical - Psychological Factors and Economic - Demographic Factors. Journal of Family and Research, Vol 1, No. 1, Autumn.

Mobini, S. (1372). Examining the role of focus of attention in memory bias in depressed patients. Vol. 2, No. 1 \& 2.

Mozafari, Sh, and Hadianfard, H. (2004). Positive Psychology - Feelings of Mental Happiness. Journal of Contemporary Psychotherapy, Vol 9, No. 31 \& 32, pp. 87-100.

Nassiri, H; Hashemi, L, and Hosseini, M. (2006). Review of Quality of Life of Students of Shiraz University based on Quality of Life Scale of World Health Organization. The presented article in global third seminar on student's mental health, Advisory Center of Student Assistant of Ministry of Science. Research and Technology and Iran University of Science and Technology. 3 and 4 Khordad.

Nejat, S; Montazeri, A; Holakouee Naeeni, K; Mohamad, K, and Majdzadeh, R. (2006). Standardization of Quality of Life Questionnaire of World Health Organization (WHOQOL-BREF): Translation and Psychometric Iranian Species. Journal of School of Hygiene and Public Health Research Institute, Volume IV, NO. 4, pp. 1-12.

Ostovar, S. (1385). Investigatingthe memory bias (cognitive) in adolescents with psychology phobic disorder, 10 (3): 39.

Repley, M. (2003). Quality of life Research, A. Critical Introduction., London: Sage, P.10-18.

Sohrabi, N, and Hosseini, M. (2002). Review of Relationship between Types of Family Relationships and Positive and Negative Affection in Feminine and Masculine Students Resident in Dormitories. Iran's First Congress on Psychology. Teacher Training University, Tehran.

Soltanizadeh, M; Malekpour, M; and Neshat doost, H.t (2008). The Relationship between Physical Pleasure and Positive and Negative Affection in Students of Isfahan University. Psychological Studies. Al-Zahra University-Faculty of Education and Psychology. Volume IV, No. 1, Spring, pp. 32-46.

Stong, A.A. (1981). The association between perception of daily experiences and self- and spouse- rated mood. Journal of Personality and Social Psychology, 52, 56-58.

Telligen, A. (1995). Structure of mood and personality and their relevance to assessing anxiety. With an emphasis on self- report. In A. H. Tuma., \& D. Maser (Eds). Anxiety and the anxiety disorder (PP. 681-706). Hillsdale, NJ:Erlbaum.

Waston, D.; Clark, L.A. \& carey. G. (1988). Positive and negative affect and their relation to anxiety and depressive disorder. Journal of abnormal psychology. 97-346-359.

Watson, D., Clark, L.A. \& Tellegen, A. (1988). Development and validation of a brief measure of positive and negative affect: the PANAS scales, Journal of Personality and Social Psychology. 54, 1063-1070. 